\title{
Field tests of micropatch and prey-size selection by Snail Kites Rostrhamus sociabilis
}

\author{
GODFREY R. BOURNE \\ School of Natural Resources, The University of Michigan, Ann Arbor, Michigan 48109, \\ $U S A$
}

Accepted 7 February 1984

\begin{abstract}
Six free-living Snail Kites Rostrhamus sociabilis were tested for preference by density for micropatches and size of apple snails Pomacea dolioides in simultaneous choice situations. Two hypotheses were tested: kites respond differentially to varying densities of larger versus smaller size classes of snails, foraging where the expected yield is greater; and kites are capable of selecting the larger size classes from a variety of available snail size classes. Kites preferred to forage in micropatches with high prey density. Variation among kites with respect to prey-size selection was very small. In Experiments I and III there were significant inverse correlations between kite choice and snail size, but no relationship was demonstrated in the other test. Significant differences were found between mean individual weights of snails taken by kites and those not taken in Experiments I and III. No differences were observed in Experiment II. Selectivity indices show that the larger size classes were taken above their availability, although no statistical relationship existed between kite choice and snail abundance. These results corroborate the two hypotheses and suggest that kites use hierarchical decision making by employing density of snails to select appropriate feeding locations before selecting the largest individuals from those locations.
\end{abstract}

Field observations of Snail Kite Rostrhamus sociabilis foraging behaviour indicates that it prefers the high-prey-density habitats and the larger size classes of apple snails Pomacea dolioides (Beissinger 1983). However, it has not been demonstrated whether kites alter their preference for particular foraging locations or snail size classes as the numbers and sizes of available snails change. I conducted a series of field experiments in late July 1980 in Guyana, South America, to elucidate the factors influencing micropatch and prey-size selection by these raptors.

A useful theoretical approach to the study of foraging is to focus on the hierarchical decisions supposedly made by predators (Gass $\&$ Montgomerie 1981, Orians 1981). First, the predator selects its general habitat; second, it selects a foraging patch within that habitat; and finally, it chooses among the different prey types encountered within the patch. This hierarchical decision making is the heart of optimization approaches to patch and prey selection which have recently become commonplace in ecology (see reviews in Pyke et al. 1977, Krebs et al. 1983). According to this theory, predators feed in places and on food items that maximize caloric or nutrient return per unit effort and risk. Predators probably cannot evaluate directly a prey's energetic or nutrient content prior to ingestion (Freed 1980); however, all else being equal, larger prey probably have higher energetic and nutrient content (i.e., they are more valuable food items), and prey density reflects the value of a patch for feeding (i.e., it provides higher food return per unit of feeding effort).

There is still much to be learned about the mechanisms that allow the discrimination of micropatches and prey items by free-living predators, especially under natural conditions. Therefore, I presented free-living Snail Kites with various combinations of densities and snail sizes in micropatches to test whether: (1) kites respond differentially to varying densities of larger versus smaller size classes of snails, foraging where the expected yield is greater (Schoener 1971); and (2) kites are 
capable of selecting the larger size classes from a variety of available snail size classes within a micropatch.

\section{MATERIALS AND METHODS}

\section{PREDATOR AND PREY}

Snail Kites are ideal organisms for testing hypotheses about predator choice of feeding location and prey by size. They are medium-sized raptors that are easily observed while foraging because they inhabit open fresh-water marshes. Kites capture single prey and return to one of several perches to ingest their food (see Snyder \& Snyder 1969, Voous \& van Dijk 1973). Their diet is relatively easy to quantify (Bourne \& Berlin 1982, Beissinger 1983) because kites feed almost exclusively on amphibious prosobranch snails of the genus Pomacea (Haverschmidt 1970 , Snyder \& Snyder 1969, Snyder \& Kale 1983), the discarded undamaged shells can be collected from under the kites' feeding perches (Beissinger 1983), and mass or energy content estimated from linear measurements (Bourne \& Berlin 1982). Pomacea spp. surface to inspire air (McClary 1964) and it is near the surface that they are susceptible to Snail Kite predation (Snyder \& Snyder 1971).

\section{FIELD EXPERIMEN'TS}

The study was carried out at the Guyana National Park $\left(6^{\circ} 50^{\prime} \mathrm{N} ; 58^{\circ} 10^{\prime} \mathrm{W}\right)$, Georgetown, Guyana, from 24 to 29 July 1980. Experiments were curtailed after kites failed to appear in the study area on $30 \mathrm{July}$, and none were located at other coastal sites.

Twenty medium (20-25 g) P. dolioides were provided in each of two $1 \times 1 \times 0.25 \mathrm{~m}$ pens set $1 \mathrm{~m}$ apart that were partially submerged in a large ditch (see Bourne $\&$ Berlin 1982) three days before the start of the experiments, to habituate the free-living kites to the experimental set-ups. Each patch was stocked with snails on the preceding night, and the patch covered until the following morning. The covers were gently removed just prior to the run of a training session or a test, to minimize disturbance of the snails (see Snyder \& Snyder 1971). The training period was conducted from 24 to 26 July, during which time six adult (two females and four males) individually recognizable kites learned to use the patch. From the time I introduced the patches some kites became territorial when the pens were open (see Snyder \& Snyder 1970). Therefore, patch locations and hence the territorial Snail Kites were chosen at random for the actual tests. Not all snails were visible to the foraging kites because of water turbidity, and because individual snail surfacing behaviour varied (McClary 1964).

Starting on 26 July I stocked one patch with 20 large snails $(23-59 \mathrm{~g})$ and the other with 20 smaller snails $(8-16 \mathrm{~g})$. This snail density was comparable to that of the big ditch and consisted of the mean plus one standard deviation. The smaller snails were of sizes eaten by the kites, but below the mean for snails selected from this ditch. I determined randomly in which patch to place large or small snails, to prevent kites from predicting which of the two patches was more profitable (sensu Royama 1970). Two tests were conducted each day for $1 \mathrm{~h}$ between $0630-0730 \mathrm{~h}$ and $1600-1700 \mathrm{~h}$ (Guyana Standard Time), the peak foraging time for kites (pers. obs.). After the morning tests, the patches were randomly relocated, restocked with snails and covered until it was time to conduct the afternoon test. This was a replicate of the morning experiment. All snails used in these tests were individually weighed (Bourne \& Berlin 1982), and numbered. After a particular snail was captured and ingested, its numbered shell was immediately retrieved from under the kite's feeding perch. The snail's identification number and its ordinal capture rank was recorded. 
The order in which the three experiments were conducted was randomly determined. Thus, Experiment I was run on 27 July to determine kite preference between two groups of snails (previously discussed) presented in equal densities in simultaneous choice situations. On 28 July, Experiment II was designed primarily to test micropatch choice by providing kites with equal weights but unequal densities of large (20) in one patch and smaller snails (54) in the other patch. Finally, Experiment II I was conducted on 29 July by presenting kites with equal mixes of larger (10) and smaller (10) snails in each patch.

\section{SELECTION ANALYSIS}

Snails were assigned to $5 \mathrm{~g}$ size categories. I used the 'Freed-Alford' electivity model (Freed 1980) to determine prey selection indices for the resultant ten size classes of snails:

$$
e_{i}=\frac{\sum_{j(i)}\left(\frac{1}{n_{i(j)} / N}\right)\left(\frac{1}{R_{j}}\right)}{\sum_{j(i)}\left(\frac{1}{n_{i(j)} / N}\right)}
$$

where $e_{i}$ is the electivity index that ranges from 0 (size class is completely ignored by the kite) to 1 (kite specializes on that size class; $n_{i(j)}$ is the number of snails of size class $i$ present just prior to the capture of snail $j$ of the size class $i$; $N$ is the total number of all snails of all size classes present just prior to the capture of snail $j$; and $R_{j}$ is the ordinal rank of snail $j$ captured by a kite.

A discussion of the rationale and utility of this electivity model is presented by Freed (1980). Its outstanding features are: (1) it emphasizes a predator's ability to type-select as the absolute abundance of the preferred prey type decreases; (2) it accounts for the relative abundance of prey types at each capture; and (3) because the system is closed and without prey replacement, rank order of prey capture is paramount (Freed 1980).

\section{RESULTS}

Tested Snail Kites course-hunted (see Snyder \& Snyder 1969, Beissinger 1983) throughout the experiments because their feeding perches were $c .50-150 \mathrm{~m}$ from the micropatches. Foraging kites stalled when over the patches and quickly scanned the two patches before rapidly descending to select a snail. This two-decision process probably took less than $1 \mathrm{~s}$.

Snail Kites exhibited preferences for certain patches. In Experiment I they made significantly more visits (i.e., each independent trip to capture a snail) to the patch with larger snail size classes $\left(\chi^{2}=4.80\right.$, d.f. $\left.=1, P<0.05\right)$. Kites also made significantly more visits to the very high-density patch which contained the smaller snail size class in Experiment II $\left(\chi^{2}=5.82\right.$, d.f. $\left.=1, P<0.05\right)$. However, no patch preferences were observed in Experiment III $\left(\chi^{2}=0.04\right.$, d.f. $\left.=1, P>0.05\right)$, where equal mixes of both small and large size classes were presented to the foraging kites in both patches.

No significant differences were found between individual Snail Kites within replicates of each experiment with respect to prey-size selection (Wilcoxon Rank Sum Test, $P<0.25$ ). In Experiments I and III there were significant negative correlations between kite preference and snail weight, but no significant relationship was demonstrated in Experiment II (Table 1). These findings are echoed by the results in Table 2, where significant differences exist between the mean individual weights of snails taken by kites and those not selected. Once again no statistical 
TABLE 1

Spearman's coefficient of rank correlation $\left(\mathbf{r}_{\mathbf{s}}\right)$ for two predator-prey parameters (2tailed test). $N$ is the number of snails selected and snail-size classes available to Snail Kites for selection, respectively.

\begin{tabular}{|c|c|c|c|c|}
\hline Experiment & Correlation & $n$ & $r_{s}$ & $P$ \\
\hline $\begin{array}{l}\text { I } \\
\text { II } \\
\text { III }\end{array}$ & $\begin{array}{l}\text { Prey rank in diet } v \text {. prey weight } \\
\text { Prey rank in diet } v \text {. prey weight } \\
\text { Prey rank in diet } v \text {. prey weight }\end{array}$ & $\begin{array}{l}30 \\
29 \\
29\end{array}$ & $\begin{array}{r}-0.48 \\
0.25 \\
-0.61\end{array}$ & $\begin{array}{l}<0.01 \\
>0.05 \\
<0.01\end{array}$ \\
\hline $\begin{array}{l}\text { I } \\
\text { II } \\
\text { III }\end{array}$ & $\begin{array}{l}\text { Prey rank in diet } v \text {. prey abundance } \\
\text { Prey rank in diet } v \text {. prey abundance } \\
\text { Prey rank in diet } v \text {. prey abundance }\end{array}$ & $\begin{array}{l}7 \\
9 \\
8\end{array}$ & $\begin{array}{r}0.05 \\
-0 \cdot 15 \\
0.07\end{array}$ & $\begin{array}{l}>0.05 \\
>0.05 \\
>0.05\end{array}$ \\
\hline
\end{tabular}

differences were found in Experiment II (Table 2). Generally, electivity indices indicate that larger size classes of snails tended to be taken by Snail Kites above their availability (Fig. 1). However, there were no significant correlations between snail size classes selected and the abundance of size classes presented to the kites in all three tests (Table 1).

\section{DISCUSSION}

\section{MICROPA'TCH SELECTION}

In this study Snail Kites preferred micropatches with higher densities of snails. In Experiment II they showed a preference for the very high density patches with the smaller snails. Apparently, this unusally high density of the smaller snail size classes may have functioned as a supernormal releaser (Tinbergen 1951) for the kites. These results suggest that kites used a hierarchical decision making strategy while foraging, i.e., (1) they selected the general habitat (of no concern in this study), (2) then a foraging patch, and (3) finally a prey type (Gass \& Montgomerie 1981, Orians 1981). It seemed impossible for kites to override certain cues while foraging, at least over the short term, (e.g., very high density of smaller snails for less abundant larger snails). Therefore, kites may be relying on a simple rule of thumb that allows them to

\section{TABLE 2}

Mean weight \pm one standard deviation $(g)$ of Pomacea dolioides preferred by Snail Kites in simultaneous choice tests and significance probabilities (P) resulting from Wilcoxon Rank Sum Test

\begin{tabular}{lcccc}
\hline Experiment & Selected & $n$ & \multicolumn{1}{c}{ Mean } & $P$ \\
\hline I & Yes & 30 & $33 \cdot 28 \pm 11 \cdot 14$ & $<0.001$ \\
& No & 50 & $20 \cdot 18 \pm 11 \cdot 33$ & \\
II & Yes & 29 & $17 \cdot 73 \pm 8 \cdot 31$ & 0.553 \\
& No & 119 & $19 \cdot 01 \pm 10 \cdot 83$ & \\
III & Yes & 29 & $34.32 \pm 7 \cdot 31$ & $<0.001$ \\
& No & 51 & $17.60 \pm 9.24$ & \\
\hline
\end{tabular}




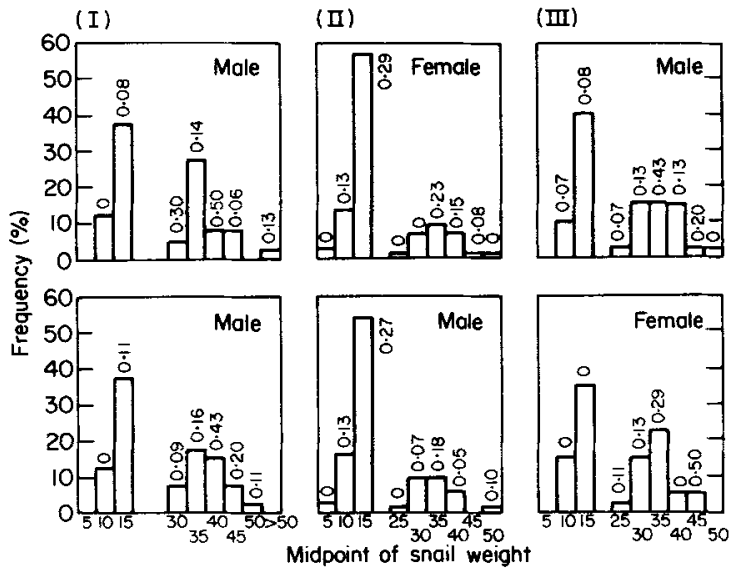

FIGURE 1. Histograms showing percentages of Pomacea dolioides in $5 \mathrm{~g}$ size classes available to Snail Kites in simultaneous choice tests. The sex of each kite tested is indicated. Electivity coefficients are shown for snail size classes selected by the kites in three experiments with replicates: (I) equal densities of small versus large snails, (II) equal weights but unequal densities of small and large snails, and (III) equal mixes of small and large snails in each patch.

forage where prey abundance is highest, and where under natural conditions it may lead to kites maximizing their energy intake.

In Experiment III no selection of patches was seen. This was expected because each patch contained equal densities and equal numbers of small and large snails. Even though densities were equal in Experiment I, I suspect that the patch with the larger snail size classes appeared to be more dense to kites than the patch with the smaller snails, because larger snails spent more time at or near the water's surface (pers. obs.). Other field studies by Goss-Custard (1970), Smith (1974a,b), Hartwick (1976), Tinbergen (1981), and Hulscher (1982), demonstrated that Redshank Tringa totanus, thrushes Turdus spp., Black Oystercatchers Haematopus bachmani, Starlings Sturnus vulgaris and Oystercatchers $H$. ostralegus, respectively, congregate in areas of high prey density where profitability, i.e., the quantity of any prey that could be captured in a given time spent foraging (Royama 1970) is presumably higher. However, two recent studies demonstrated that free-living raptors do not choose foraging sites strictly on the basis of prey density, but on accessibility, preferring areas of relatively low cover (Baker $\&$ Brooks 1981, Bechard 1982). Beissinger (1983) showed how important accessibility is to Snail Kite foraging. He found that kites abandoned rice-culture habitats as feeding areas after rice Oryza sativa plants emerged several $\mathrm{mm}$ above the water's surface and made access to snails difficult. However, the wading, tactile feeding Limpkin Aramus guarauna continued to feed on snails in these same areas (Beissinger 1983). These various studies suggest that birds prefer to hunt in areas where profitability is quite high, and that density is only one factor contributing to profitability. Accessibility was not a factor in my study, and the hypothesis that kites feed where the expected yield is greater is generally supported. Probably kites use snail density as the higher order foraging cue before apparently relying on snail size (discussed below) to discriminate among encountered prey.

\section{PREY SELECTION}

In Experiments I and II, Snail Kites selected the larger size classes of snails when presented with a choice. In the first test, kites not only selected the larger snail size 
classes but also selected the largest individuals first. As depletion of the patch with the larger size classes proceeded ( $\cong 50 \%$ ), they took only five smaller snails from the other patch. However, these kites chose the larger individuals of the small snails. During the morning test in Experiment III the male kite chose larger snails before selecting some individuals of the small size classes (Fig. 1). The female, on the other hand, completely ignored the small size classes during the afternoon test, even though she foraged in both patches. She behaved as predicted by contingency optimal foraging models (e.g., MacArthur \& Pianka 1966, Schoener 1969, Charnov 1976), and supported in tests cited in Krebs et al. (1983). This female was highly selective, ignoring the small prey, but choosing the equally abundant larger snails.

It has been demonstrated that with greater prey abundance selection for the preferred prey is increased in many animal species (see Krebs et al. 1983). However, in this study (Experiment II) the preferred larger snail size classes were initially ignored by the kites for the more abundant smaller snail size classes. No large snails were included in the kite's diet until late in the test.

The less-than-perfect correlations between kite choice of prey by size, and the detectabilities of the various size classes were probably due to the interactions of several environmental and biological factors. First, the turbidity of the water in the ditch probably prevented the foraging kites from seeing all of the snails during each fly-over. Second, there was much variation in individual snail surfacing behaviour. Smaller snails had higher surfacing rates (Burky \& Burky 1977). But, larger snails tended to stay longer at the surface (pers. obs.). This behaviour may have been influenced by parasites (Croll 1968). Older, larger snails have greater parasite loads (S. Hanning pers. comm.) and may therefore spend more time at the surface, thus becoming more prone to kite predation. The net effect is that large snails spend more time overall at the surface than do small snails. Third, these anomalies indicate that Snail Kites, like other predators, are not 'all knowing', as contingency models assume (Pulliam 1974, Charnov 1976). Furthermore, Krebs et al. (1983) indicated that predators sample their environment, a contention that appears to be supported by this study. Predators also make detection errors, may take longer to distinguish among prey types, and have to learn the relative profitabilities of the prey types (Krebs et al. 1983).

However, since Beissinger (1983) measured Snail Kite handling times for three size classes of snails (small, medium and large), and found no significant differences for each size class, the profitability of a particular snail is related solely to its size (i.e., large snails are more valuable to kites as food). According to optimal foraging theory, it is assumed that predators can distinguish among prey of different profitabilities and that they choose the more profitable items. Since profitability of snails increases with size, larger snails should be preferred, and indeed a disproportionate number was selected by kites. The overall results on prey selection by kites corrobrate the hypothesis that Snail Kites are capable of selecting the larger size classes from a variety of available size classes. Thus, Snail Kites appear to discriminate among alternative prey by size, and attempt to rank them in order to feed efficiently.

In conclusion, this evaluation of two correlates of optimal foraging (i.e., prey density and size), and actual tests of contingency optimal foraging models under field conditions (e.g., Goss-Custard 1977, Davies 1977, Pulliam 1980, Sutherland 1982) imply that predators select the most profitable prey. But as Sutherland (1982) indicates, the means of prey selection were not elaborated. He suggests two probable mutually exclusive mechanisms of prey selection, either (1) predators evaluate the profitability of prey encountered and choose the most profitable, or (2) they may rely on a general rule which allows them to select the largest prey and this results in them choosing the optimal diet. 
This paper is part of a Ph.D. thesis submitted to the University of Michigan. Support was provided by the University of Michigan through a Rackham Graduate Fellowship, a Rackham Dissertation Grant, and a School of Natural Resources Grant to graduate students. Additional funding came from the Chapman Memorial Fund of the American Museum of Natural History, Sigma Xi Grant-in-Aid Program, and Jane E. Stevens. President Linden F. S. Burnham of Guyana permitted me to land my equipment, materials and supplies duty free. Special thanks to Gregory Bourne and Joyce Fredericks for assisting in the field, and to Chris Hoogendyk who provided assistance with statistical analyses. I am grateful for comments made on various stages of the manuscript by Steve Beissinger, Gary Belovsky, Eric Bolen, Gary Fowler, Steve Lima, Bobbi Low, Mark Ritchie, and Robert Storer.

\section{REFERENCES}

BAKER, J. A. \& BroOks, R. J. 1981. Distribution patterns of raptors in relation to density of Meadow Voles. Condor 83: 42-47.

BECHARD, M. J. 1982. Effect of vegetative cover on foraging site selection by Swainson's Hawk. Condor 84: $153-159$

Beissinger, S. R. 1983. Hunting Behavior, prey selection and energetics of Snail Kites in Guyana: consumer choice by a specialist. Auk 100: 84-92.

Bourne, G. R. \& Berlin, J. A. 1982. Predicting Pomacea dolioides (Reeve) (Prosobranchia: Ampullariidae) weights from linear measures of their shells. Veliger 24: 367-370.

BURKY, K. A. \& BURKY, A. J. 1977. Buoyancy changes as related to respiratory behavior in an amphibious snail, Pomacea urceus (Müller), from Venezuela. Nautilus 91: 97-104.

Charnov, E. L. 1976. Optimal foraging: attack strategy of a mantid. Am. Nat. 110: 141-151.

Croll, N. A. 1968. Ecology of parasites. Cambridge: Harvard University Press.

Davies, N. B. 1977. Prey selection and social behaviour in Wagtails (Aves: Motacillidae). J. Anim. Ecol, 46: $441-469$.

Freed, A. N. 1980. Prey selection and feeding behavior of the Green Treefrog (Hyla cinerea). Ecology 61: $461-465$.

Gass, C. L. \& MONTGOMERIE, R. D. 1981. Hummingbird foraging behavior: decision-making and energy regulation. In Kamil, A. C. \& Sargent, T. D. (eds.), Foraging behavior: ecological, ethological, and psychological approaches. pp. 159-194. New York: Garland STPM Press.

Goss-CustaRD, J. D. 1970. The response of Redshank (Tringa totanus L.) to spatial variations in the density of their prey. J. Anim. Ecol. 39: 91-113.

Goss-CustaRD, J. D. 1977 . Optimal foraging and the size selection of worms by Redshank, Tringa totanus, in the field. Anim. Behav. 25: 10-29.

HaRTwick, E. B. 1976. Foraging strategy of the Black Oystercatcher (Haematopus bachmani Audubon). Can. J. Zool. 54: 142-155.

HAverschmidT, F. 1970. Notes on the Snail Kite in Surinam. Auk 87: 580-584.

Krebs, J. R., Stephens, D. W. \& Sutherland, W. J. 1983. Perspectives in optimal foraging. In Brush, A. H. \& Clark, G. A. Jr. (eds), Perspectives in Ornithology. pp. 165-216. New York: Cambridge University Press.

MacArthuR, R. H. \& Pianka, E. R. 1966. An optimal use of patchy environment. Am. Nat. 100: $603-609$.

MCClary, A. 1964. Surface inspiration and ciliary feeding in Pomacea paludosa (Prosobranchia: Masogastropoda: Ampullariidae). Malacologia 2: 87-104.

OrIANS, G. H. 1981. Foraging behavior and the evolution of discriminatory abilities. In Kamil, A. C. \& Sargent, T. D. (eds), Foraging behavior: ecological, ethological, and psychological approaches. pp. 389-405. New York: Garland STPM Press.

Pulliam, H. R. 1974. On the theory of optimal diets. Am. Nat. 108: 59-74.

Pulliam, H. R. 1980. Do Chipping Sparrows forage optimally? Ardea 68: 75-82.

Pyke, G. H., Pulliam, H. R. \& Charnov, E. L. 1977. Optimal foraging: a selective review of theory and tests. Quart. Rev. Biol. 51: 245-276.

RoYAMA, T. 1970. Factors governing the hunting behaviour and selection of food by the Great Tit (Parus major L.). J. Anim. Ecol. 39: 619-668.

SCHOENER, T. W. 1969. Models of optimal size for solitary predators. Am. Nat. 103: 277-313.

Schoener, T. W. 1971. Theory of feeding strategies. Ann. Rev. Ecol. Syst. 2: 369-404.

SMITH, J. N. M. 1974a. The food searching behaviour of two European thrushes. I. Description and analyses of the search paths. Behaviour 48: 276-302.

Sмгтн, J. N. M. 1974b. The food searching behaviour of two European thrushes. II. The adaptiveness of the search patterns. Behaviour 49: 1-61.

SNyder, N. R. F. \& KaLE II, H. W. 1983. Mollusk predation by Snail Kites in Colombia. Auk 100:93-97.

SNYDER, N. F. R. \& SNYDER, H. A. 1969. A comparative study of mollusk predation by Limpkins, Everglade Kites and Boat-tailed Grackles. Living Bird 8: 177-223.

SNYDER, N. R. F. \& SNYDER, H. A. 1970. Feeding territories in the Everglade Kite. Condor 72: $492-483$.

Snyder, N. R. F. \& Snyder, H. A. 1971. Defenses of the Florida Apple Snail Pomacea paludosa. Behaviour 40: 175-215.

Sutherland, W. J. 1982. Do Oystercatchers select the most profitable cockles? Anim. Behav. 30: 857-861.

Tinbergen, J. M. 1981. Foraging decisions in Starlings (Sturnus vulgaris L.). Ardea 69: 1-67.

Tinbergen, N. 1951. The study of instinct. New York: Oxford University Press.

Voous, K. H. \& VAN DIJK, 'T. 1973. How do Snail Kites extract snails from their shells? Ardea 61: 179-185. 